Journal of Energy and
Environmental Sustainability
Journal homepage : www.jees.in

\title{
Intermodal and Intelligent Transportation Systems for Indian Transport Sector
}

\author{
Avinash Kumar Agarwal ${ }^{1, *}$, Akhilendra Pratap Singh ${ }^{1}$, Sukrut S. Thipse $^{2}$, Mukti Prasad $^{3}$ \\ ${ }^{1}$ Engine Research Laboratory, Department of Mechanical Engineering, Indian Institute of Technology Kanpur, Kanpur-208016, India \\ ${ }^{2}$ The Automotive Research Association of India, Vetal Hill, Paud Road, Kothrud, Pune-411038, India \\ ${ }^{3}$ Technology Information Forecasting and Assessment Council, Department of Science and Technology, New Delhi-110016, India
}

\section{A R T I C L E I N F O}

\begin{tabular}{ll}
\hline Received & $: 25$ June 2019 \\
Revised & $:$ 10 July 2019
\end{tabular}

Accepted : 04 October 2019

Keywords:

Intermodal transport,

Intelligent transport system,

Sustainability, Road transport.

\begin{abstract}
A B S T R A C T
Various studies showed that the quality and robustness of road transport infrastructure network greatly impact the economic growthand poverty alleviation efforts of any country. Over last couple of decades road connectivity has improved across the most parts in India, however, further improvements are essential for fuelling the economic growth. Road transport infrastructure development in India has been an insurmountable challenge because of variety of reasons. Recent infrastructure connectivity efforts in India deal with integration of road networks at various rail-heads, major river ports and sea ports via appropriate highways. Regional road network infrastructure projects are usually more difficult and expensive than national road infrastructure projects, particularly in the hilly and inaccessible terrains. Intermodal connectivity, therefore, plays a vital role in seamless movement of people and goods from one point to another. Government initiatives such as increased use of containerization, Multimodal Transport Act (1993) and implementation of goods and services tax (GST) are few mile-stones, which are expected to strengthen evolutionary march of India towards an efficient integrated transport ecosystem. This paper presents the current status of Indian road transportation sector, with special emphasis on intermodal transport. To enhance the impact of intermodal transport, role of intelligent transportation system (ITS) is also discussedin detail. Hence this article provides future pathways for intermodal transport and application of ITS in the Indian road transport sector.
\end{abstract}

\section{Highlights:}

- Development of integrated transport system.

- Intermodal connectivity for seamless movement of people and goods

- Emphasis on intermodal transport in India.

- Intelligent transportation system (ITS) for sustainable road transport.

\section{Introduction}

An efficient transportationsystem is one of the most important requirements for the economic growth of any country. In most countries, transport systems have four distinct segments namely roadways, railways, waterways, and airways ${ }^{[1]}$. Homogeneous distribution of these segments is critical for a sustainable transport system and it is a challenge to maintain its uniform distribution. In Indian transport system, number of vehicles on the roads has increased significantly due to increase in population, improvement in living standard and average income levels, and inadequate public transport facilities. Statistics shows that the $\sim 40 \%$ of India's population will be residing in urban areas by 2035 and this would lead to the increased traffic congestion, severe pollution, longer commute times and huge burden on economy due to higher fuel consumption ${ }^{[2]}$. Economists have presented one other perspective of rapidly increasing numbers of vehicles on Indian roads. They suggested that the costs of vehicle usage on roads should be divided into two categories namely private costs and externality costs. All tangible costs towards fuel, tolltax, parking, and vehicle maintenance constitute private cost, however unintended costs due to traffic congestion, air, water and noise pollution, traffic accidents and deterioration of the roads comprise the externality costs ${ }^{[2-3]}$. The sum of these two i.e. private costs and externality costs is the true social cost of a vehicle ${ }^{[3]}$. Currently, vehicle owners have to pay only private costs and they do not pay directly for the traffic congestion and environmental costs associated with their vehicular use on the roads. Therefore it is important to consider these factors during policy making related to transport sector. Currently, only very few factors are taken into consideration and only traditional assessment methods are used, which cover only desired effects and excludes other important effects resulting from processes other than the desired processes. This results in exponential increase in the number of vehicles plying on the roads. Unplanned vehicle management is another important issue associated with an unplanned evolution of road transport sector ${ }^{[4-5]}$. In such scenario, multi-modal transportation system (MMTS) along with the intelligent transportation system (ITS) have the potential to resolve the issues adversely impacting the current transport system in India ${ }^{[1,6]}$. Combination of these two systems is capable ofmanaging traffic movement to reduce congestion and hence it would reduce Green House Gas (GHG) emissions from the road transport sector ${ }^{[7-8]}$. Subsequent sections of this article discuss the features, benefits, and challenges of MMTS and ITS.

\footnotetext{
* Corresponding Author: : akag@iitk.ac.in
} 


\section{Multi-Modal Transportation System (MMTS)}

In India, the growth of vehicles has increased substantially due to rapid increase in population, urbanization and explosive growth in commercial and industrial activities. In transport sector, both passenger and freight transport are equally important. Movement of goods requires a series of logistics, which includes different transport modes such as railways, waterways, and roadways depending upon freight lot size, available travel options, and journey length. In goods transport, all modes of transport are equally important, however in passenger transport, rail and road transport dominate in India. In goods transport, it is very important to connect one mode of transport with the other in order to enhance the overall effectiveness of the entire journey. This would also lead to reduction in the carbon foot-print of transport sector from the environmental viewpoint. MMTS exploits coordinated and judicious use of multiple modes of transport for faster, safer, and comfortable movement of people, especially in urban areas. It provides convenient and economical inter-connection amongst various transport modes to cover entire journey from origin to the destination in a comfortable and cost-effective manner. MMTS is traditionally characterized by high capacity, easy accessibility and appropriately located nodes ${ }^{[8]}$. In MMTS, each mode of transport is combined seamlessly, which yields the lowest cost of transportation, and lowest environmental impact for the entire supply chain.

There are two important aspects of MMTS, which makes this solution compatible with the Indian transportation sector. First, MMTS plays an important role in international trading and affects movement of goods between different countries. Movement of goods in hinterland of the country affects the regional development. Using effective MMTS, various customized items can be imported from developed countries, which are otherwise difficult to produce indigenously. Second, MMTS can effectively reduce the transportation cost and environmental impact by reducing the contribution of road transport in movement of bulk cargo ${ }^{[8-9]}$.

Energy and environmental efficiency is the prime benefit of intermodal transport however accessibility is the main challenge for using two or more modes of transport collectively ${ }^{[6]}$. Figure 1 shows a typical intermodal transport system. Most goods export require trucks, or railway wagons for pickup, transport or delivery during the supply chain in any economy. Intermodal transport system competes favourably with the conventional road dominated transportation in terms of costs and time. Even a railbarge intermodal transport system would have lower transport cost than an all rail freight movement and this is the reason, India is planning major projects for coastal transport and river highways using large number of barges. Shipping of value-added goods is more or less reliable but transit times are slightly higher in the intermodal transport settings. Hence, potential time savings in intermodal transport remains a key competitive challenge for making it more effective solution for bulk-transport needs in India.

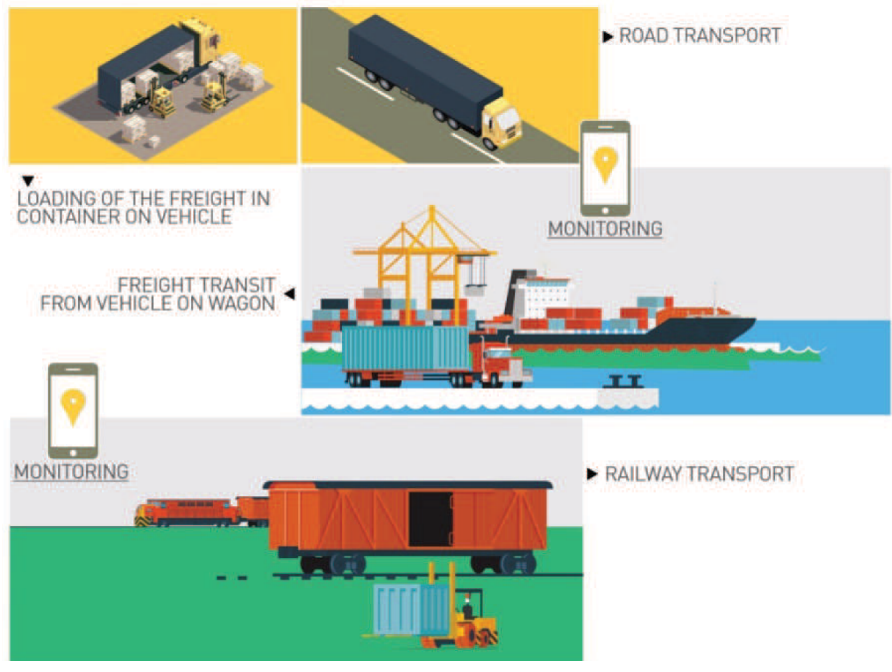

Figure 1: Intermodal Transport [5]

Reliability and transit time of movement are significantly affected by level of connectivity between different transport modes. Any obstacle that slows or halts the flow of traffic creates a bottleneck. Traffic congestion is the most occurring event, which slowsdown the traffic movement and leads to queue formation. This results in negative impact on the economy and leads to environmental pollution. Bottlenecks may be due to lack of infrastructure or due to unfavourable regulatory framework and in some cases, dysfunctional supply chain ${ }^{[10-11]}$.

Operations of MMT systems are complex, which require serious efforts in planning. System integration with new advanced technologies that support data acquisition and information management remains the key challenge. These systems also integrate hardware and software components into a multi-functional platform, specifically designed for planning and monitoring of MMTS. A schematic representation of MMTS is given in Figure2.

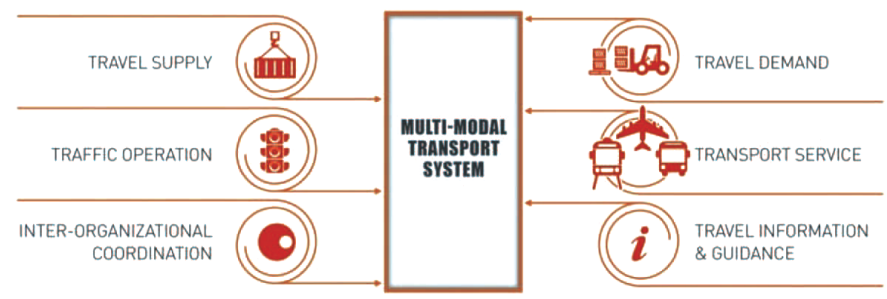

Figure 2: Components of MMTS [1]

Connectivity deals with all levels of transit service coverage. Smooth connectivity is helpful in integrating routes, making schedules, and patterns of spatial activity. Main objective of connectivity is to quantify and evaluate transit services in terms of prioritizing transit locations and assessing its effectiveness and efficiency. A typical schematic of the intermodal connectivity for public transportation is shown in Figure 3.

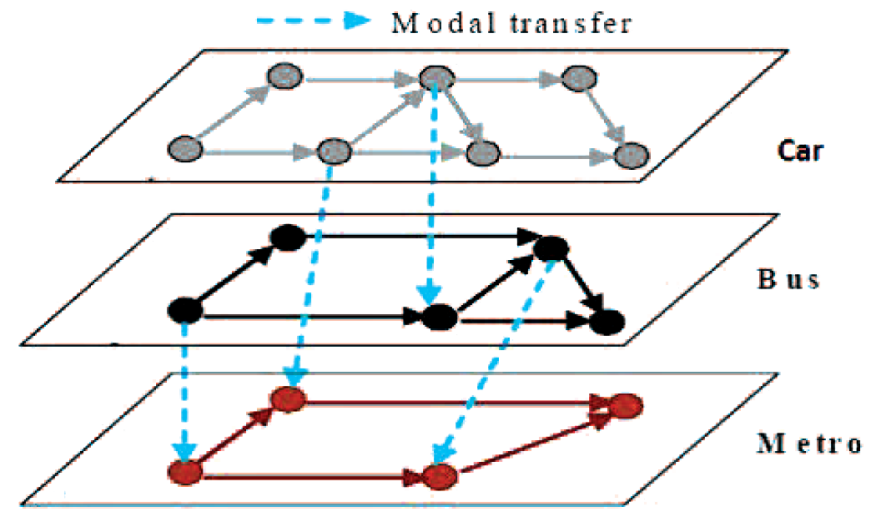

Figure 3: Schematic of Intermodal Public Transport System [12]

Such intermodal public transport system (IPTS) contains several layers (modes) such as metro, car, bus, etc. and connectivity between these layers is the critical requirement of a successful IPTS. In a typical IPTS commuters can drive and park their personalised transport at the nearest bus station to ride a bus and then change over to a metro at a suitable transit point ${ }^{[12-14]}$. Many developed countries have already deployed such IPTS to avoid typical road transport issues. In India, efforts are made to establish such multi-model connectivity in Delhi and Hyderabad. Some other cities planning metro networks are also considering deploying the same model.

\subsection{Modal Shifts in Public Transport}

An important alternative to using personal cars, scooters or other personalised vehicles is use of an efficient public transport system. Major cities in India such as New Delhi, Bangalore, Mumbai, etc. are emphasizing on raising the share of public transport and discourage the use of personalised transport ${ }^{[1]}$. India has made a commitment to reduce GHG emissions in intended nationally determined contribution (INDC) report to the tune of 33-35\% per unit GDP by 2030 w.r.t. the base year 2005 . GHG emission issue was also discussed extensively in the Climate Change Conference of Parties (COP-21) in Paris from $30^{\text {th }}$ November to $12^{\text {th }}$ December 2015 and India is committed to it. Transport sector in India contributed $13.5 \%$ of the total emission in the year 2013, of which, road transport sector contributed the maximum to the tune of $80 \%{ }^{[15]}$. 
Shifting from public transport to a public transport dominated economy could be one of the strategies to meet these commitments ${ }^{[16-17]}$. Several cities have formulated strategies and made investments plans for expansions of existing roads, local railway lines, changes in bus/ tram fleet, and efforts to provide inter-connectivity (park and ride). Some cities such as Mumbai, New Delhi, etc. have already achieved significant share of public transport in the transportation ecosystem ${ }^{[1,15]}$. In some cities, there are well-developed networks, while others are currently under planning/ expansion stages. A broad range of measures are taken and implemented to improve and promote use of public transport. Several lines were expanded, frequency of services increased, information flow is enhanced and ease accessibility is improved. New travel modes such as 'light metro' or 'mono-rail' have been implemented in several cities in India, similar to other cities in developed world. Real-time information availability to the citizens has been improved over a wide range of IT media about the realtime schedule of transport services to make the usage efficient and userfriendly.

\subsection{Intermodal Connectivity of Rail, Road, and Ports}

The efforts for development of regional infrastructure to connect one country from another in Asia have been reasonably matured. However in India, historically, poor rail and road connectivity affected cargo movement and the concept of intermodal transport evolved rather slowly. There is still a great scope for further improvement in rail-road connectivity with the major ports. Maritime infrastructure greatly facilitates international trade, thus spurring the economic growth. Therefore intermodal connectivity is one of the important port performance indicators. Intermodal connectivity is absolutely relevant because many ports can handle a larger share of these volumes with seamless assistance of intermodal transport methodologies. Connectivity of roads with the ports is very important for intermodal transport and better connectivity between ports and intermodal terminals in the hinterland can really enhance the share of intermodal transport systems. Approximately $70 \%$ of all container volumes are handled by sea ports in India. Cargo handled at the 12 major ports in India has increased to $>400$ million tonnes. Government of India has emphasised on development and modernisation of the port infrastructure in order to become globally competitive. Currently, ports are unable to handle additional traffic because of slow evacuation of cargo from the ports due to rather inefficient intermodal connectivity. Therefore despite having adequate capacity and modern cargo handling facilities and infrastructure, ports are unable to ensure a quicker ship movement, which undermines the competitiveness of Indian ports in global arena. Therefore it is essential that intermodal connectivity of major ports with the hinterland is supplemented on a priority basis to ensure sustained economic growth and bottlenecks in freight movement is minimised.

\section{Intelligent Transport System}

India's transport sector is large and diverse and comprises of four modes: road, rail, water, and air. With roads as one of the dominant mode of transport carrying $60 \%$ of freight and $87 \%$ of passenger traffic coupled with limited road space, roads are facing traffic congestion, delay in travel time, air pollution and accidents. The per capita penetration of vehicles is increasing year-on-year and it is projected that cars/ SUVs will grow 13fold and 2-wheelers will grow 6.6 folds by 2035 compared to 2005 levels ${ }^{[18]}$.

At this point in time, Indian Railways, the second largest railway network in the world, carries $\sim 15$ million passengers and 165,000 tons of freight per day on its wide-spread network of 64,000 route kilometers, marred with overcrowding and overloading, and faces severe capacity constraints. Shipping and in-land waterways being the most environmentfriendly and cheapest modes of transport, which are yet to be fully develop to cope up with the current requirements of the country and are not utilized to the extent required. Modal share of various transport systems in India is given in Table 1.

\begin{tabular}{|l|c|c|}
\hline $\begin{array}{c}\text { Mode of } \\
\text { Transport }\end{array}$ & $\begin{array}{c}\text { Passenger } \\
\text { (Passenger kilometre, } \\
\text { PKM) }\end{array}$ & $\begin{array}{c}\text { Freight } \\
\text { (Tonne Kilometre, } \\
\text { TKM) }\end{array}$ \\
\hline Road & $86.1 \%$ & $66.4 \%$ \\
Rail & $12.6 \%$ & $33.3 \%$ \\
Air & $1.3 \%$ & $0.1 \%$ \\
Water & N.A. & $0.2 \%$ \\
\hline
\end{tabular}

Prevailing challenges of imbalance in different modes of transport (Table 1), lack of connectivity, inadequate infrastructure, and its suboptimal use are some of the factors that need to be addressed to improve connectivity in India. In last 60 years, India has developed a long road network however, there are few factors, which hamper seamless freight movement in the length and breadth of the country. Institutional barriers such as multiple checks during the transit and poor-quality of road infrastructure are some of the major factors, which need to be addressed for efficient transport system evolution. Presently there are 177 interstate check posts and 268 toll barriers on national highways result in congestion, leading to longer travel time ${ }^{[19]}$. A smooth-functioning multi-model freight transport system thoroughly connected with ITS is vital for seamless flow of goods, which affects the economy of any country. It helps inefficient loading/unloading and transfer of goods via terminals at various locations. It is also useful for reliable vehicle performance, minimum number of halts/detentions enroute, and very high utilisation levels for fixed assets of the system.

ITS can provide a number of technical solutions for challenges posed by rapidly increasing surface transportation problems in mega-cities of India. ITS uses advanced technologies for communication and control to improve mobility, safety, maximize the energy efficiency and environmental protection. ITS is a term used to refer to several interdependent transport modes and road technologies and offers to check traffic congestion, air pollution and road safety using intelligent communication systems.

Figure 4 shows various components of ITS and its broad applications.

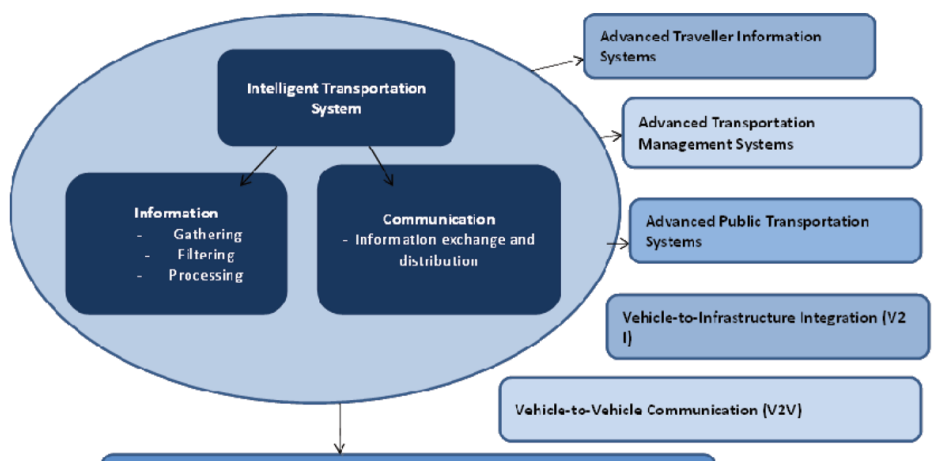

Vehicle-to-passenger-to-Infrastructure (V2P2I)

Figure 4: Components and applications of ITS

ITS is, therefore, enabler for technologically advanced transport infrastructure, which enhances safety and mobility by integration of computer, electronics and communication technologies ${ }^{[20]}$. ITS comprises of various wired and wireless technologies for superior management of traffic. It enables exchange of information for better management and use of available resources and facilitates smooth flow of real-time travel and traffic related information such as transit routes and schedules, navigation direc-tions, real-time information about traffic congestions, road accidents/ blockages/construction, weather conditions, etc. ${ }^{[21]}$. It thus facilitates interactions between various components of the transport system, users, vehicles, and infrastructure via one integrated communication system.

Information and communication technology (ICT) plays an important role in revolutionizing the ITS. Intelligence can be embedded at all levels of the system e.g. in the vehicles and its subsystems, in the surrounding infrastructure, in the energy supply chain, in the traffic management system and in the services delivered by the system. ITS is not only restricted to road transport sector alone but also it plays an important role in other transport modes such as railways, waterways, airways, and MMTS Internet of Things (IoT) makes the communications amongst different sub-system components possible thereby enabling a new realm of optimization and automation.

Investments in highway capacity yield a benefit-cost ratio of 2.7-to-1 however, application of ITS technologies can substantially improve this ratio further up to 9-to-1. ITS has demonstrated drastic improvements in traffic management and road safety in several countries worldwide. Therefore for ITS, the benefits far outweigh the investments hence its implementation in India is desirable and inevitable and should to be done quickly. ITS acts as a common platform, which combines system users, vehicles and infrastructure into one integrated system so that information can be exchanged for better management and use of available resources. 
Various solutions related to ITS also improve intermodal transfers by enhancing the flow of information between different transportation modes and improve overall reliability.

The adoption and implementation of various applications of ITS as an integral component of the transport system has already been done in various developed countries such as USA, Canada, Europe, Japanand has shown dramatic improvements in the safe and efficient mobility of people there ${ }^{[21]}$. Whereas in India, ITS implementation has not yet reached a comparable level w.r.t. existing successful ITS systemsof these nations.In India, few applications of ITS have already been introduced though, mostly in metropolitan cities such as ITS for parking management, electronic tolls, tracking of public transport, etc. ${ }^{[22-23]}$. However, these systems are standalone ITS systems demonstrated and deployed in few major cities such as Delhi, Mumbai, Hyderabad, Pune, Bangalore, and Chennai. A fully developed ITS application connecting various applications, and areas and communicating seamlessly is absent as of now in India but it is evolving slowly. Various challenges in the implementation of ITS in India are as follows:

- Lack of user awareness

- High cost of these systems (for installationin passenger/ private vehicles).

- Lack of integration between the components, which are already deployed.

- Lack of definite guidelines and regulations, as well as absence of national ITS standards for different ITS applications.

- Need to develop ITS services specifically suitable for Indian scenario: such as congestion management, traffic management, commercial vehicle operations, etc.

ITS technologies play a major role in the smart city program in India ${ }^{[24]}$

Some of the key ITS technologies are:

(a) Smart Card: Smart card, which is a card enabled with a smart chip has already been deployed in India. This card allows vehicle users to pay for any public transport charges by using this single smart card. This enables seamless entry of MMTS in mega-cities of the country.

(b) Electronic Toll Collection: Electronic toll collection systems are Radio Frequency Identification (RFID) based systems, which are capable of reading tags from a distance and can automatically debit the toll at the instant of each passing. This technology reduces the travel time, traffic congestion and fuel consumption increase due tohalting at toll collection booths. In India, this technology has already been adopted on the Mumbai-Pune expressway and more such electronic toll collection infrastructure is being installed on other expressways.

(c) Smart Parking Assist: Use of sensors for various applications in modern vehicles is increasing rapidly. For parking, the vehicle, the chassis and the driveline are equipped with sensors and cameras. This technology increases safety, efficiency, and comfort in driving and smooth parking in congested areas.

(d) Automated Speed Enforcement: The new generation automated speed programs allow controlling vehicle speeds and prevent accidents. Vehicle speed reduction is another important step to prevent road accidents due to congestion and heavy traffic. Further, automated red light and automatic traffic management also helps in speed limit enforcement, thus saving precious human lives.

(e) RFID Tags: It is useful for tracing the vehicles and also can be used for tracking vital components such as fuel cylinders. RFID tags store information, which can be retrieved by scanners from a distance.

\section{Intelligent Roads}

Infrastructure connectivity is a pre-requisite for the transportation of people and freight, it enables integration of economic activities, access to markets generates employment and creates investment opportunities. Intelligent roads aim at addressing the needs of road users by improving driver's awareness of sudden changes in the road conditions, information on pavement safety and real-time traffic information based on dynamic traffic data and safety status updates. New and audacious approaches are required to increase the road capacity. Regular road maintenance policies should also be implemented for adding intelligence in the existing road network infrastructure rather than building new roads. Innovative integration of various sensors and ICT with the road infrastructure is an important potential solution for achieving the twin objectives of increased road safety and enhanced road capacity. This can be achieved at significantly lower cost and easily compared to costs involved in making new roads thereby providing a cost effective solution. This technology can be potentially used in India in future since the country is required to make some serious investments for developing new road infrastructure, which can be potentially reduced by using intelligent roads. A typica schematic of intelligent road and its components are shown in Figure 5 This shows that the future of ITS relies on super-intelligent vehicles, infrastructure, control systems, planning, and driver acceptability of these technologies. Legislation would play a key role in ensuring and encouraging the use of such intelligent, futuristic technologies in India e.g. communication among vehicles or between the vehicle and the infrastructure would happen only when it is legalized in the country.

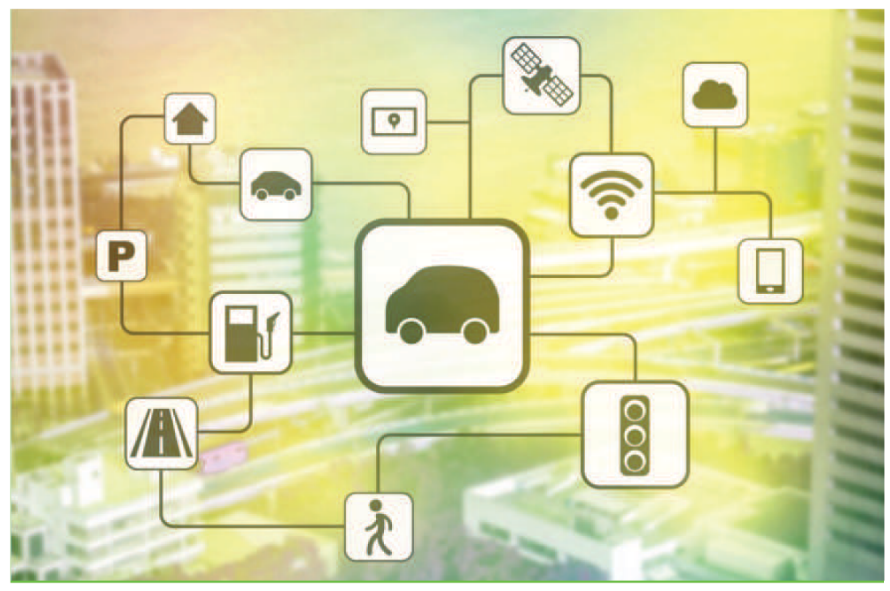

Figure 5: Schematic of Intelligent Roads and its Components ${ }^{[1]}$

This infrastructure development will require investments, both from public and private sector and special purpose bodies will be required to be constituted in order to implement these projects in fast-track mode. ITS will be key enablers for improving vehicle safety and would contribute to resolve traffic management issues in India.

\section{Inspection, Maintenance \& Certification}

The physical condition of the vehicle is extremely important factor since it affects the private costs as well as the externality costs. Hence a planned vehicle inspection, maintenance, and certification program should be implemented in order to monitor the health of vehicles plying on Indian roads, which will tangibly improve the road worthiness of these vehicles and associated safety issues that they cause.In India, setting increasingly stringent emissions norms for new vehicles will have lower impact without providing an effective solution for existing vehicles plying on Indian roads. This will only have a lasting effect if it is backed witha reliable system of inspection and maintenance for in-use vehicles Therefore a law should be adopted and enforced for regular and effective vehicle inspections, including a comprehensive and functional emission evaluation. A reliable inspection and maintenance program should be launched nation wide to measure and control emissions especially for the fleet of younger vehicles, which will be used for next several years and vehicles older than 10 or 15 years should be taken off the roads. Based on transport vehicle data of 2012, roughly 160 million vehicles are plying on Indian roads. It is estimated that 300 light-duty and 320 heavy-duty I \& M centres will be required in India by 2020 .There are many loopholes in the current inspection practices, which require significant modifications in the implementation practices, especially for trucks and busses. A planned training module should be implemented for each sector therefore suitable infrastructure and adequate financial, political and public support should be garnered. Poor vehicle maintenance significantly affects the total emissions from the road transport sector. A research carried out by Baidyaa et al. ${ }^{[25]}$ showed $>19 \%$ increase in NOx emissions and $>68 \%$ increase in $\mathrm{CO}$ emissiondue to poor inspection and maintenancepractices of the on-road vehicles (Figure 6). They also suggested that suitable maintenance of vehicle would result in $>20 \%$ and $>51 \%$ reduction in total NOx and $\mathrm{CO}$ emission respectively ${ }^{[25]}$. Similarly, lower mileage of old vehicles would also result in relatively higher emissions of $\sim 10 \%$ higher $\mathrm{CO}, \sim 4 \%$ higher $\mathrm{HC}, \sim 2 \%$ higher $\mathrm{NOx}$ and $\sim 5 \%$ higher $\mathrm{PM}$

Suitable modifications in the construction material used for road infrastructure development and adaptation of modern road construction technologies will result in lower maintenance costs for the road network thus reducing traffic disruptions due to lower road maintenance/ constructions. Use of light-weight materials for putting up temporary structures can relieve congestion during road maintenance and reduce 


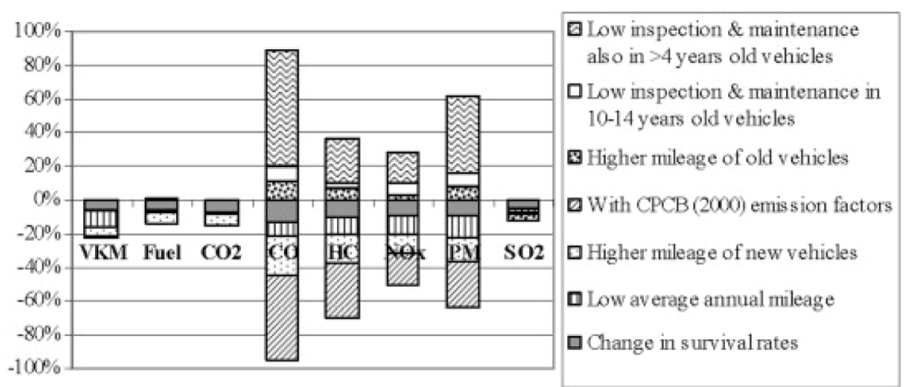

Figure 6: Effect of Vehicle Maintenance and Life on Emissions ${ }^{[25]}$

the need for diversions, which will ultimately reduce traffic disruptions and travel time. Poor condition of roads is a major issue in India, which is mainly due to lack of appropriate maintenance protocols and practices. Due to inappropriate fund allocation may be a possible reason for this in which funds for the maintenance of the National Highways are not allocated in planned annual budget. Most of the road maintenance support comes from the non-planned budget, which leads to inadequate financial support for infrastructure maintenance for the national and state highways. In such a scenario, it is required to look for the alternative perennial sources of funds for road maintenance. Introduction of toll roads on a build-operate-transfer (BOT) basis has emerged as a potential solution for Indian road transport sector but this also has several issues. The involvement of panchayats to ensure the maintenance of rural roads may be a desirable initiative of the government for ensuring appropriately maintained road conditions in localised regions in rural areas. Similarly, some other out-of-the-box initiatives need to be explored to strengthen the maintenance of road network in the length and breadth of India.

With the increase in the population of vehicles on the Indian roads, it is important to adopt new policy for regular inspection and maintenance on-road vehicles, so that safe and environmental friendly road travel can be ensured. Most inspection and maintenance tests conducted today are highly subjective and spurious. During these tests, no test database is generated. There are seasonal limitations for conducting these tests. Keeping this in mind, Government of India has embarked upon an Inspection and Certification regime, which seeks to establish vehicle inspection and certification (I\&C) centres throughout the country. The ten centres planned in the country are shown in Figure 7.

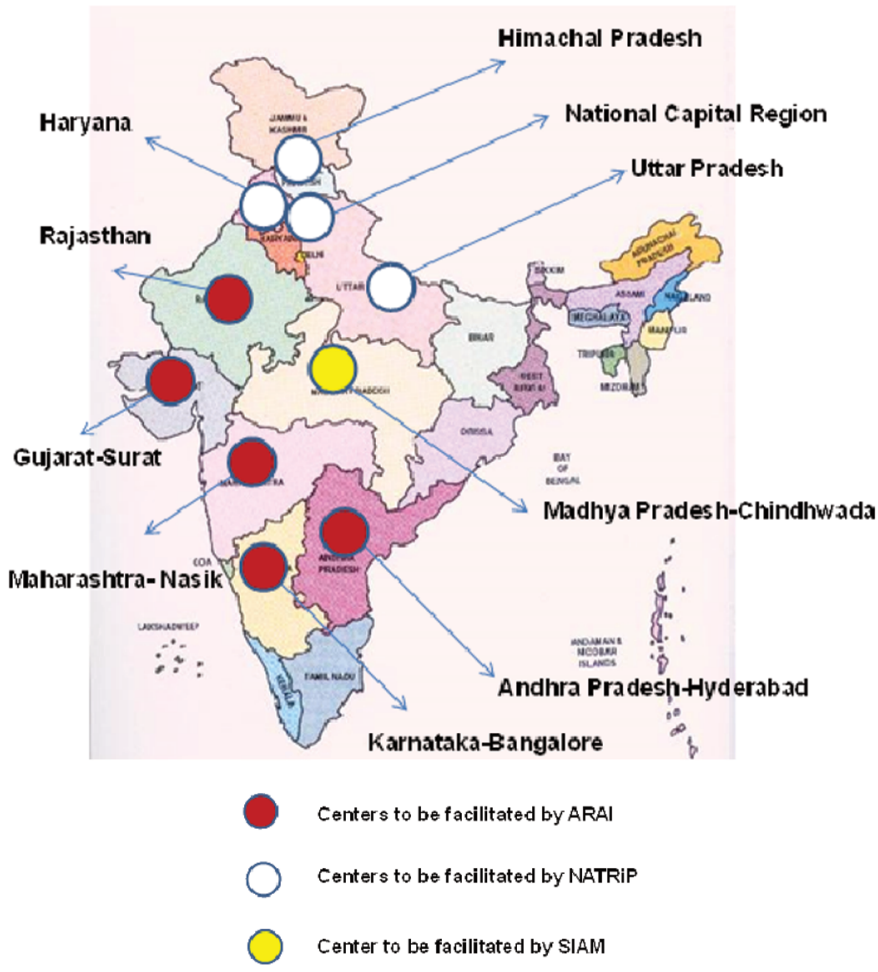

Figure 7: Vehicle I\&C Centres planned in India ${ }^{[26]}$

\section{Conclusions and Recommendations}

The agenda for improving the Indian road transport sector can be divided into two categories namely short term actions, which need to be implemented within next five years; and medium term actions, which can be implemented in five to ten year time-frame.Short term action items included:

- Optimization of public transport services and freight logistics based on real time information flow and response.

- Better connectivity of urban hubs with main corridors.

- Improved road network and intelligent use of road spaces.

- Intelligent monitoring of road network and its maintenance.

- India should leverage its strong IT base for indigenous development of ITS solutions.

- India can leapfrog the ITS technologies by adopting the models used in developed countries and leverage its extensive cellular and internet spread.

- Growing trend of smart phones and mobile internet usage, along with growing number of electronic control units (ECUs) fitted vehicles will help in gathering the real-time traffic information and at the same time, it will help in achieving economies of scale for implementation of ITS.

Medium term actions items include the following.

- Expansion of existing road network having long life and durable structures.

- New policy for construction/maintenance of roads on the basis of road-life costs.

- Conversion of busy roads to intelligent road by extensive use of ICT for enhancing the road usage efficiency and reducing congestion.

- Minimize 'down-time' for maintenance and accident clearance to avoid traffic disruptions.

\section{Acknowledgements}

The authors declare that there is no conflict of interest. Some parts of this article are taken from the "TV-2035: Technology Roadmap for Transportation", published byTechnology Information, Forecasting, and Assessment Council (TIFAC), NewDelhi, which was also co-authored by the authors of this article. The authors would like to acknowledge TIFAC for giving permission to use parts of the report in this paper. The efforts of TV-2035 advisory committee Chairman Sh. Shrikant Marathe, and other members is gratefully acknowledged. Their valuable suggestions helped the authors in crystallising their ideas. Valuable suggestions of Dr. Prabhat Ranjan and Dr. Gautam Goswami, TIFAC are also acknowledged. Authors would also like to acknowledge the financial support from Department of Science and Technology, Government of India for undertaking the TV-2035 exercise.

\section{References}

[1] TV 2035, "Roadmap Report on Transport Sector", Technical report published by TIFAC, 2016.

[2] Report on "World Urbanization Prospects", Department of economic and social affairs. Published by the United Nations. ISBN 978-92-1-151517-6.

[3] B.J. Kanninen. Intelligent transportation systems: An economic and environmenta policy assessment. Transportation Research Part A: Policy and Practice 1996; 30(1): 1-10.

[4] K. Zavitsas, I. Kaparias, Michael G. H. Bell. Transport problems in cities. $7^{\text {th }}$ Framework Programme Coordination of Network Descriptors for Urban Intelligent Transport Systems (CONDUITS), Imperial College London, 2010.

[5] R. Arnott, K.A. Small. The economics of traffic congestion: Rush hour driving strategies that maximize an individual driver's convenience may contribute to overall congestion. American Scientist 1994; 82:446-455.

[6] L.K. Nozick, E.K. Morlok. A model for medium-term operations planning in an intermodal rail-truck service. Transportation Research Part A: Policy and Practice 1997; 31(2):91-107.

[7] D. Briggs, C. de Hoogh, J. Gulliver, J. Wills, P. Elliott, S. Kingham, K. Smallbone A regression-based method for mapping traffic-related air pollution: application and testing in four contrasting urban environments. The Science of the Total Environment 2000; 253:151-167.

[8] Report on "Developing India's first modern inland waterway". April 2017. http:/ /www.worldbank.org/en/country/india/brief/developing-india-first-moderninland-waterway, Accessed on $23^{\text {rd }}$ June 2017.

[9] G.S. Dwarakish, A.M. Salim. Review on the Role of Ports in the Development of a Nation. Aquatic Procedia 2015; 4:295-301.

[10] B. Hamilton-Baillie, P. Jones. Improving traffic behavior and safety through urban design. Proceedings of the Institution of Civil Engineers - Civil Engineering 2005; 158:39-47. 
[11] R. Arnott, A. Palma, R. Lindsey. Does providing information to drivers reduce traffic congestion? Transportation Research Part A: General 1991; 25(5):309318.

[12] Gawade M., "Intermodal Performance Measurement of Multimodal Public Transportation System", Ph.D.Thesis, University of South Florida, 2009.

[13] Y.M. Bontekoning, C. Macharis, J.J. Trip. Is a new applied transportation research field emerging? A review of intermodal rail-truck freight transport literature. Transportation Research Part A: Policy and Practice 2004; 38(1):1-34.

[14] A.E. Haghani. Formulation and solution of a combined train routing and makeup, and empty car distribution model. Transportation Research Part B: Methodological 1989; 23(6):433-452.

[15] S.K. Lohia. Urban Transport in India. Report of Ministry of Urban Development.

[16] N. Paulley, R. Balcombe, R. Mackett, H. Titheridge, J. Preston, M. Wardman, J. Shires, P. White. The demand for public transport: The effects of fares, quality of service, income and car ownership. Transport Policy 2006; 13:295-306.

[17] G. Barnes. The importance of trip destination in determining transit share. Journal of Public Transportation 2005; 8:1-15.

[18] Railway handbook 2016, Energy consumption and $\mathrm{CO}_{2}$ emission, IEA \&UIC.

[19] Report on "Toll Barriers on National Highways" Ministry of Road Transport \& Highways, Government of India, 2011.
http://pib.nic.in/newsite/PrintRelease.aspx?relid=75222 accessed on $23^{\text {rd }}$ September 2017.

[20] C. Bester. Explaining national road fatalities. Accident Analysis and Prevention 2001; 33:663-672

[21] S. Grant-Muller, M. Usher. Intelligent Transport Systems: The propensity for environmental and economic benefits. Technological Forecasting and Social Change $2014 ; 82: 149-166$

[22] S.E. Shladover. Potential contributions of intelligent vehicle/ highway systems (IVHS) to reducing transportation's greenhouse gas production. Transportation Research Part A: Policy and Practice 1993; 27(3):207-216.

[23] D.C. Shoup. The trouble with minimum parking requirements. Transportation Research Part A 1999; 33:549-574.

[24] S. Mehra, S. Verma. Smart Transportation-transforming Indian cities. Report issues by Ministry of Road Transport, Highways, and Shipping, Government of India, 2016.

[25] S. Baidyaa, J. Borken-Kleefelda. Atmospheric emissions from road transportation in India. Energy Policy 2009; 37(10):3812-22.

[26] ICT Standards and Emerging Technologies, EBTC March-2014. 